\title{
TANGO - a screening tool to identify comorbidities on the causal pathway of Nocturia.
}

WF Bower ${ }^{1,2}$, GE Rose ${ }^{3}$, CF Ervin ${ }^{2}$, J Goldin $^{3}$, DM Whishaw ${ }^{4}$, F Khan ${ }^{1}$

${ }^{1}$ Department of Rehabilitation Services, Royal Melbourne Hospital

${ }^{2}$ Sub-Acute Community Services, Royal Melbourne Hospital

${ }^{3}$ Department of Respiratory and Sleep Medicine, Royal Melbourne Hospital

${ }^{4}$ Department of Aged Care; Department of Urology, Royal Melbourne Hospital

Royal Park Campus, Royal Melbourne Hospital

34-54 Poplar Road, Parkville.

VICTORIA. 3052.

AUSTRALIA

Keywords: nocturia; aetiology; diagnosis; TANGO; screening

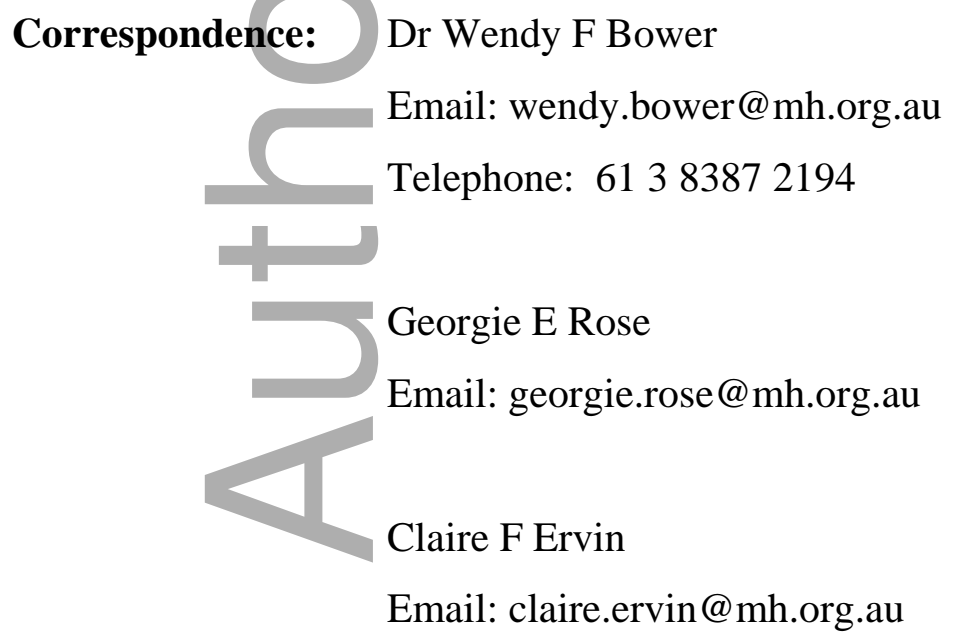

This is the author manuscript accepted for publication and has undergone full peer review but has not been through the copyediting, typesetting, pagination and proofreading process, which may lead to differences between this version and the Version of Record. Please cite this article as doi: 10.1111/bju.13774

This article is protected by copyright. All rights reserved 
Dr Jeremy Goldin

Email: jeremy.goldin@mh.org.au

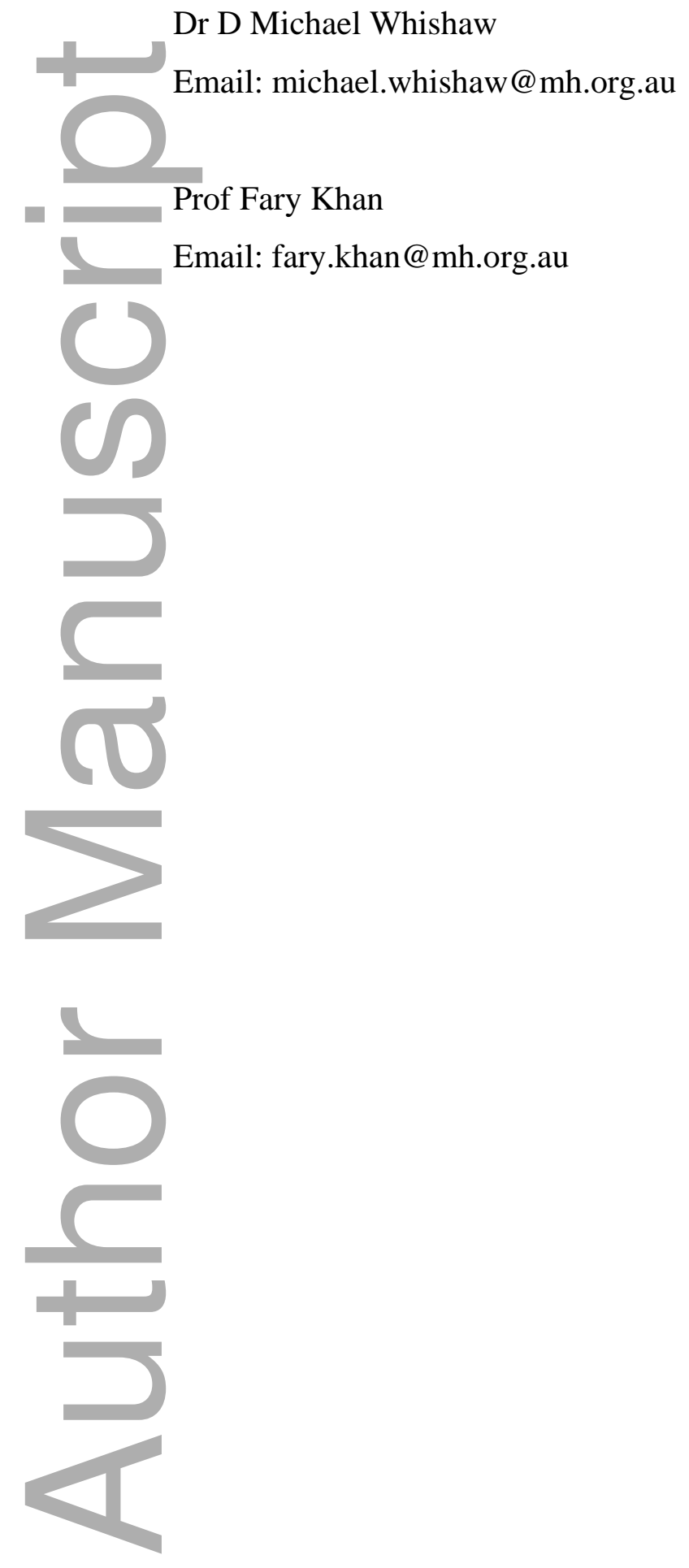

This article is protected by copyright. All rights reserved 

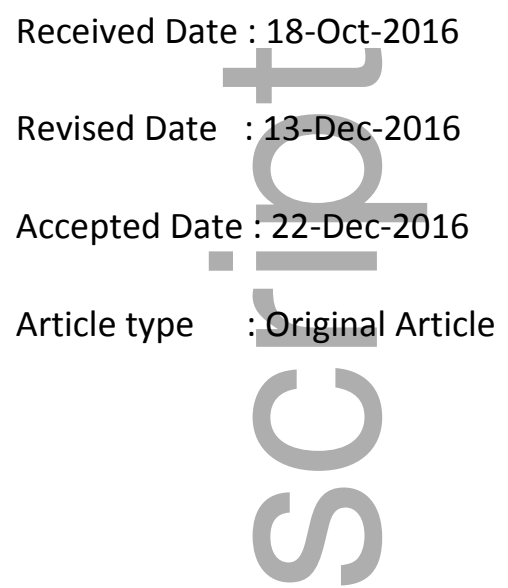

\section{Article category: Translational Science}

\section{Abstract \\ Objectives}

To develop a robust screening metric for use in identifying non-lower urinary tract comorbidities pertinent to the multidisciplinary assessment of patients with nocturia.

\section{Methods}

Variables having a significant risk association with nocturia of greater than once per night were identified. Discriminating items from validated and reliable tools measuring these comorbidities were identified. A self-completed 57-item questionnaire was developed and a medical checklist and pertinent clinical measures added. Pre-determined criteria were applied to retain or remove items in the development of the short form screening tool.

\section{Subjects/Patients}

The tool was administered to 252 individuals with nocturia who were attending either a tertiary level Sleep, Continence, Falls or Rehabilitation service for routine care. Data collected was subjected to descriptive analysis; criteria were applied to reduce number of items. Using predetermined domains, a nocturia screening metric, entitled TANGO, was generated. The acronym TANGO stands for Targeting the individual's Aetiology of Nocturia to Guide Outcomes. 


\section{Results}

The demographic characteristics of the sample are described, along with item endorsement levels. The statistical and structural framework to justify deleting or retaining of items from the TANGO Long Form to the screening Short Form is presented. The resultant short form patient-completed nocturia screening tool is reported.

\section{Conclusions}

A novel all-cause diagnostic metric for identifying co-existing morbidities of clinical relevance to nocturia in patients who present across disciplines and medical specialties has been developed. TANGO has the potential to improve practice and smooth inequalities associated with a siloed approach to assessment and subsequent care of patients with nocturia.

\section{Introduction}

Individual causes are unlikely to be sufficient or necessary to produce nocturia (1); there are likely to be multiple "backdoor" causal pathways. Although solid evidence exists that factors such as prostatic enlargement and nocturnal polyuria are linked to a high frequency of nocturia, waking to void is likely to represent an interaction of causes, often outside the urinary tract system (2-4). Given that episodes of nocturia are more often seen in individuals with poor or fair health than in people reporting a good health status, the symptom itself may be a surrogate marker of impaired wellbeing.

Common practice in patients with nocturia is to identify relative polyuria at night, as a proportion of total 24-hour urine production, detect prostatic enlargement, ascertain the presence of bladder overactivity and observe the lower legs for evidence of peripheral oedema $(5,6)$. Each of these factors can be causative of nocturia and warrant examination. However, the greatest risks attached to frequent nocturia appear to be where dysfunctions co-exist i.e., individuals either using sedatives or complaining of secondary insomnia who also report falls, women with a poor health status or disordered breathing, anxiety or impaired cognition as a co-morbid diagnosis in either gender, the presence of both restless leg syndrome and secondary insomnia and men with nocturia who also have elevated inflammatory markers(1). The possible combinations of co-existing symptoms cross discipline and system-specific expertise.

Patients may not proffer the symptom of nocturia at a medical appointment for a systemic or unrelated disorder, believing it to be trivial and not worth reporting (7). This belief does not align This article is protected by copyright. All rights reserved 
with older people reporting frustration, a negative impact on quality of life, tiredness, inconvenience and reduced function as a result of nocturia (8). Nor does it reflect the personal and healthcare costs associated with nocturia. Under-reporting of nocturia may reveal a taboo around waking at night to void and indicate that the symptom is ubiquitous or considered a hallmark of ageing.

In reality, patients with nocturia are more likely to present with complex medical issues than with nocturia as a single symptom of concern. Clinicians are well aware that unmanaged nocturia carries significant morbidity, even when stratified for age and known risk factors. In order to ensure best care for patients with nocturia, health professionals need to be confident that all possible causes of the symptom have been identified. There is currently no screening instrument or diagnostic pathway for nocturia that includes evaluation of relevant dysfunction in multiple body systems. A clinical tool that captures information about aspects of nocturia and causal comorbidities is necessary.

The aim of this study was to develop a brief patient-completed screening tool for use in identifying potential and co-existing causes of nocturia. The metric was required to capture clinically relevant variables, critical items that may show a low level of endorsement and questions representative of the breadth of implicated domains. Furthermore, the screening metric should contain items from validated tools.

\section{Methods}

We have previously described a literature search undertaken to identify studies clarifying the relationships between nocturia $\geq$ once per night and markers of poor health, and reported significantly associated risk factors (1). In developing the TANGO screening tool, the previously identified domains of health status, mental health, cardiovascular, metabolic, inflammation and sleep disorders were utilised. The index question established the frequency of nocturia at night and the bother this caused.

\section{Materials}

Validated and reliable patient-completed instruments that captured the presence of variables specific to each domain, and that were significantly associated with nocturia, were identified (9). Given that retaining all items from the separate validated measures in the screening tool was unwieldy, a clinical judgement discrimination process was undertaken. Individual items were scrutinised to identify questions relevant to nocturia or that could be considered key discriminators of different health system domains. Items that were non-specific or duplicated in other tools were 
not selected. Questions for each domain were extracted separately from the different tools, combined and grouped together in the TANGO screening form long version. In summary, questions included on the TANGO Long Form were selected from a number of robust measures of other health issues and grouped under the domains of interest to nocturia (i.e. cardiovascular / metabolic dysfunction, sleep issues, urinary tract symptoms, wellbeing). Clinical measures indicative of associated risk factors were identified and similarly scrutinised; height, weight, blood pressure in supine, sitting and standing, heart rate, hip, waist and neck size and walking speed using the Timed Up and Go Test were added to the screening form. Content validity was established by cross checking the domain-specific items of each of the identified pre-existing validated metrics against the variables in the TANGO Long Form. This process has been previously described (9).

Pilot testing of the final version of TANGO Long Form was conducted in 20 individuals and included cognitive interviewing of five respondents. The process revealed no issues with the measure. After pilot testing, the TANGO long form comprised 57 questions and 10 clinical measures.

\section{Population}

Psychometric analysis traditionally obtains precision of estimates from a sample size of approximately 250 data sets; however, our tool was not designed to give a total score and therefore did not require a specific number of subjects. Instead, we selected participants representative of mid to older aged adults with nocturia who would have the characteristics of patients the screening tool is intended to be used with. The study recruited 252 individuals 40 years or older who woke at night to void and who were presenting for care at the Royal Melbourne Hospital Continence, Rehabilitation, Falls and Balance or Sleep Disorders outpatient clinics, or, who were inpatients on either the Aged Care or Rehabilitation wards. Clinical services involved in the study reflected the target population who suffer from nocturia. The eligibility age of 40 was selected in order to include capture of data from the typical population attending for assessment of sleep apnoea.

Individuals with any of the following conditions that may be associated with atypical nocturia were ineligible for inclusion: receiving end-of-life-care, terminal malignancies, end stage renal disease, bladder cancer, previous pelvic radiotherapy, pregnancy, dementia requiring supervision, or cognitive impairment that precluded questionnaire completion. Similarly, individuals who were medically unstable were excluded from the study. 


\section{Process}

The study was ratified by Melbourne Health Human Research Ethics Committee (EC00243); approval number LNRSSA/16/MH/64. Patients registering for a hospital clinic appointment in any of the participating services within our institution were handed a flyer by clerical staff describing the prospective questionnaire study. If during their healthcare appointment they reported an interest in participating in the study, the patient information material and consent form were presented. Study staff then explained the process for self-completing the questionnaire and permitting the 10 physical measures. The time burden estimated was approximately 15 minutes. Individuals agreeing to participate in the study signed a written consent form. Participants completed the TANGO questions and physical measurements before leaving the hospital.

Participants signed an informed consent allowing their self-completed and physical measurement data to be used in the study. As the TANGO Long Form was anonymous no attempt was made to link participant's data sets with medical record details of concurrent illness. De-identified coded data was entered into a tailored password-protected database.

\section{Statistical analysis}

Data was entered into the statistical database SPSS (V23); demographic, social and physical characteristics of the sample were tabulated. Endorsement of items was investigated; those with a high floor effeet (i.e. $>70 \%$ of responses "never" or its equivalent), an inter-relationship $>0.6$ or $>20 \%$ missing data were noted.

The association between individual items and severity of nocturia was established using univariate linear regression. Discrete items were analyzed separately; however, where items were part of an index, corrected item correlation (CIC) was used to rank the individual items. The dependent variable of nocturia frequency was considered both as a continuous variable and as a binary value (nocturia $<2 /$ night versus nocturia $\geq 2$ night). A logistic regression model to assess the impact of significant univariate associations on the likelihood of nocturia frequency $\geq 2 /$ night was built.

Conceptual as well as empirical and clinical factors were considered when assessing items for inclusion or exclusion in the TANGO Short Form. Missing responses and endorsement levels were included in the decision process, but subject to clinical judgement. The decision whether or not to retain items in the TANGO Short Form was the result of a process whereby items were retained if they were on a direct causal pathway to nocturia, demonstrated a significance of association with high nocturia frequency, showed high endorsement, evidenced no floor effect and were not highly This article is protected by copyright. All rights reserved 
correlated with other items. All variables were evaluated for these factors; items failing the criteria were removed. TANGO Short Form was built from retained items re-grouped into the 4 previously specified domains.

\section{Results \\ Sample

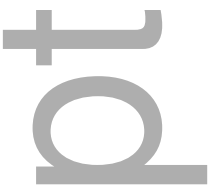

Table 1 summarises the demographic details of participants in the study and shows the mean age of participants to be 65 years (SD 12). Overall the gender split was even, although females predominated in the Continence service and males in the Sleep clinic. Only two participants identified as indigenous to Australia, New Zealand or the Pacific Islands. Education to the level of senior high school or below was reported by half the sample. Close to two thirds of participants resided in an area classified as disadvantaged.

Physical attributes reported in Table 2 indicate that participants were overweight and that metabolic risk, as indicated by an elevation in gender-specific waist-hip ratio was high in women but borderline for men. Hypertension was reported by half the sample in the questionnaire but was within normal limits when measured. One quarter of participants exhibited postural hypotension. Diabetes mellitus was reported by $30 \%$ of participants.

Overall 19\% of participants reported excellent or very good health, whilst $45 \%$ summarised their health status as fair or poor. A history of cancer was reported by $16 \%$ of participants. Just over half the participants (54\%) reported being in moderate or severe pain or discomfort and $63 \%$ identified as having limited mobility. Parkinson's Disease and Multiple Sclerosis were reported by 5 and $8 \%$ of the participants respectively. Approximately one third of the cohort described a fall within the preceding 3 months.

Frequency of nocturia ranged from one to 11 voids with a mean of 2.5 (SD 1.4). Figure 1 shows a higher number of nocturia episodes to be non-significantly associated with incremental age across the cohorts. Bother related to nocturia showed a linear relationship with frequency of episodes, with 3 voids per night being moderately bothersome (Figure 2).

\section{TANGO Long Form Items}

Endorsement scrutiny revealed poor completion of items related to the participant working outside the home or being a carer, retiree, or living alone (29\%, 33\%, 17\%, 29\% missing respectively). This article is protected by copyright. All rights reserved 
None of these items were significantly associated with nocturia severity. Other items with $>10 \%$ missing data included: kicking legs during sleep, uncomfortable breathing or snoring disrupting sleep, sleep apnoea, problematic leg veins, using medication to calm the brain and the Timed Up and Go Test. Most items showed approximately $2 \%$ missing values.

Table 3 describes the structural framework used to evaluate individual items in the TANGO Long Form. It can be seen that 22 items were significantly associated with a higher frequency of nocturia episodes $(\mathrm{p}<0.05)$. Medical issues that warranted inclusion regardless of either the level of endorsement or floor effects were kidney dysfunction, the presence of, or poorly controlled, hypertension or diabetes, the use of diuretic medication and persistent lower limb fluid accumulation. Of these, the mean number of nocturia episodes was significantly higher in participants with kidney disease $(p=0.016)$, hypertension $(p=0.040)$, lower leg oedema $(p=0.01)$ and marginally significant in participants using diuretic medication $(\mathrm{p}=0.056)$.

Figure 3 shows the decision tree underlying whether or not to retain items in the TANGO Short Form; the process resulted in 20 items, including one physical measure being retained. As the Short Form was designed to be a self-completed tool, the physical measure - Timed Up and Go walk test (time predictive of increased risk of falling) - was replaced with the item history of any falls. Two further clinically important items, known prostatic enlargement and poor glycaemic control, were included. Appendix 1 shows the resulting 22-item TANGO Short Form, with items grouped under the domains of cardiovascular or metabolic disorders, sleep conditions, urinary tract symptoms and wellbeing.

The regression model for high frequency nocturia contained 8 independent variables: general health, pain, time to first nocturia, sudden urgency, urgency incontinence, depression, hours in bed and sleep quality. The full model was statistically significant (chi square $(13, \mathrm{~N}=227)=77.47$, $\mathrm{p}<0.001$ ), indicating that the model was able to distinguish between respondents who reported nocturia frequency of $<2 /$ night and those who reported nocturia frequency $\geq 2 /$ night. The model as a whole explained between $28.9 \%$ (Cox and Snell R square) and $40.3 \%$ (Nagelkerke R squared) of the variance in nocturia frequency, and correctly classified $78.9 \%$ of all cases $(90.2 \%$ of individuals with nocturia frequency $\geq 2 /$ night).

Three of the independent variables made a unique statistically significant contribution to the model (time to first nocturia episode, urgency incontinence and sudden urgency). The strongest predictor of nocturia frequency $\geq 2$ /night was urgency incontinence, with an odds ratio of 2.52 . This indicates 
that individuals who experience urgency-related incontinence daily or more often are 2.52 times more likely to report nocturia frequency $\geq 2$ /night, controlling for all other factors in the model. The odds ratio of 0.47 for time to nocturia, indicates that for every additional minute of sleep before waking, individuals are 0.47 times less likely to report nocturia frequency of $\geq 2 /$ night.

\section{Discussion}

A simple patient-completed screening form has been developed from variables significantly associated with an increased risk of nocturia. Data from two different clinical cohorts representative of patients with nocturia has been subjected to mixed method scrutiny in order to identify multiple non-lower urinary tract variables on the causal pathway of night voiding. The TANGO Short Form will increase capture of these comorbidities in clinical practice at no expense to time or cost.

Using the domains identified in our previous work, cardiovascular or metabolic disorders, sleep variables, urinary tract symptoms, and mental health and wellbeing, items in TANGO are grouped for quick interpretation. Domains can be switched in and out depending on the clinical context. For example, a general practitioner will be fully aware of an individual patient's cardiovascular and metabolic status, sleep physicians will have captured the salient aspects of insomnia, and a continence clinician will be conversant with lower urinary tract symptomatology. The TANGO Short Form can be modified for each cohort or left in its entirety for use in a broader clinical setting.

Multiple comorbidities of a severity relevant to the aetiology of frequent nocturia can be captured by TANGO, facilitating comprehensive evaluation for co-existing causes traditionally beyond the scope of lower urinary tract symptomatology. Clinicians then have the basis for a bundled treatment approach to nocturia, by investigating and intervening for clinically relevant co-existing dysfunction. Use of TANGO may uncover for example, the need for a sleep assessment, a diabetic review, pain management or intervention for depression, all of which directly or indirectly impact the production and storage of urine overnight.

As an assessment tool for nocturia, TANGO sits alongside the evaluation of 24-hour urine production and specifically the proportion of urine generated overnight. It has been observed that the severity of nocturia correlates poorly with maximum bladder storage during the night but moderately with nocturnal polyuria (10). Currently nocturnal polyuria is classified as $>33 \%$ of global urine production occurring overnight, $>90 \mathrm{~mL}$ urine production per hour of sleep or $\geq 130 \%$ of maximum voided volume by day. Whichever definition is used, accuracy relies on patient 
measurement and recording. The integration of TANGO findings and bladder diary data may suggest multiple causal pathways for nocturnal urine overproduction that warrant exploration. Such underlying causes have been sub-classified into global polyuria (e.g. diabetes or polydipsia) or nocturnal polyuria (e.g. congestive cardiac failure, sleep disordered breathing, peripheral oedema) (11). Of the causes of nocturia related to a decreased night time bladder capacity suggested by Weiss, TANGO captures all bar calculi and prostatic enlargement (11). Clinical judgement mandated the inclusion of kidney disease, peripheral oedema, unstable diabetes mellitus, hypertension and postural hypotension in TANGO. These items did not necessarily show the highest endorsement levels or strongest univariate regression with nocturia frequency but could all lie on a direct causal pathway with nocturia.

Unfragmented sleep of 7-8 hours is required to maintain wellbeing (12). Nocturia and worry are the most common causes of sleep disturbance, being implicated in both sleep onset and maintenance dysfunction (13). TANGO distils the discriminating items related to insomnia, sleep quality and sleep disordered breathing and interprets the most clinically relevant aspects of each of these symptoms. Our analysis has shown that the following sleep variables are pertinent in patients with nocturia: sleep quality that an individual would describe as "very bad", sleep latency of 30 minutes or longer, and $\leq$ five hours of total sleep at night.

The frequency of nocturia significantly increases with the severity of sleep disordered breathing (14). Sleep apnoea involves recurrent upper airway obstruction that induces acute and chronic haemodynamic effects. During the obstructive phase negative intrathoracic pressures increase myocardial oxygen consumption and change ventricular load. Arterial blood pressure rises at the end of the apnoea episode with repetitive bradycardia, followed by tachycardia episodes during subsequent sleep. Over time patients can develop systemic hypertension, inflammation and atherosclerosis. The beneficial impact of positive pressure ventilation on respiratory patterns in people with sleep apnoea is well known, however treatment also decreases nocturnal urine volume and urine electrolyte contents, ultimately improving nocturia frequency (15). TANGO captures the indicators and comorbidities of sleep disordered breathing.

In order to facilitate the identification of lower urinary tract symptoms (LUTS) of clinical relevance to nocturia, and to ensure TANGO is useful outside the specialty of continence, five validated and discriminating bladder items have been included. As would be expected the items retained identify presentation of an overactive bladder and prostatic obstruction to voiding. In line with previous reports (16), analysis of our data indicated the median time to first nocturia episode to be three 
hours and confirmed a highly significant relationship between this interval and frequency of nocturia. TANGO includes the item "I need to get up to pass urine within 3 hours of going to sleep" to flag a likely mismatch between urine production and bladder storage.

Mental health and aspects of wellbeing impact on sleep and may induce wakefulness or early waking, known hallmarks of insomnia. Holistic management of nocturia must include an understanding of issues that impact an individual's ability to relax at night and maintain sleep. In order to identify obvious anxiety or depression the TANGO Long Form included the entire Hospital Anxiety and Depression Scale (HADS). Analysis summed the two domains separately and also scrutinized individual items. Analysis showed that the HADS anxiety domain score was not related to nocturia frequency. This is in agreement with a previous report of an unclear association between anxiety and nocturia (17).

Depression has a more robust association with nocturia, findings mirrored in the TANGO Long Form data where four of the HADS depression sub-scale items were significantly associated with high frequency of nocturia and also highly endorsed. The TANGO Short Form includes one of these items, the decision based on corrected item correlation. Layout of the tool facilitates visual screening for connected issues e.g. sleep latency.

Health status, daytime sleepiness and falls history round out the wellbeing domain of TANGO. Nocturnal voiding is known to cause fragmented sleep, fatigue and impaired daytime function (12). These extreme effects are reflected in the fact that even moderate sleep deprivation is at least as dangerous when driving as alcohol intoxication (18). Dizziness and a higher risk of falls have a clear association with nocturia and have been included in the TANGO tool to prompt clinicians to search for causes of postural hypotension, vestibular disorders, poor balance or impaired mobility. Each of these variables increases the risk of mortality and is on the direct causal pathway of nocturia, warranting identification and investigation.

Future work will extend the psychometric testing of TANGO. As the Long Form was not administered to a control group, community-dwelling participants along with individuals free of nocturia will be included in validation studies. Each of the TANGO items will be validated against bladder diary measures, smart device data capture, medical records and a LUTS specific quality of life measure. The responsiveness of TANGO to capture patient outcomes following intervention will also be tested. 
Our earlier work has shown the greatest risks attached to frequent nocturia appear to be where dysfunctions coexist. TANGO clearly highlights multiple and co-existing disorders in patients with nocturia. The metric has been designed for completion by individuals who wake more than once each night as this is the population that show the highest morbidity and are most at risk of adverse events. TANGO was developed across a wide age group and is therefore generalizable to adults from midlife onwards. Future work will establish any differences in the older cohort in residential care and ascertain test re-test reliability. Furthermore, the development of an accompanying clinical pathway for each flagged TANGO item may assist clinicians in bundling care interventions and evaluating efficacy of therapy.

\section{Conclusion}

This study has addressed the gap between nocturia arising from multiple aetiologies and the symptom being evaluated as a part of the overactive bladder. A novel patient-completed, multidisciplinary screening metric has been developed to allow capture of multiple and co-existing variables that may be co-contributing to nocturia. By assisting clinicians to tailor intervention to more than one causal factor of nocturia simultaneously, the patient outcome for this symptom that currently shows only a modest reduction after monotherapy may be improved.

\section{Acknowledgement}

The research time of WB has been supported by grants from both The Australian Bladder Foundation and Ferring Pharmaceuticals Australia.

\section{Conflicts of Interest}

Dr. Bower reports grants from Ferring Pharmaceuticals, during the conduct of the study. 


\section{References}

1. Bower W, Whishaw, DM, Khan, F. Nocturia as a marker of poor health: causal associations to inform care. Neurourol Urodyn. 2016;Apr 6.

2. Obayashi K, Saeki K, Kurumatani N. Association between melatonin secretion and nocturia in elderly individuals: a cross-sectional study of the HEIJO-KYO cohort. J Urol. 2014;191(6):1816-21.

3. Drake MJ. Should nocturia not be called a lower urinary tract symptom? Europ Urol. 2015;67(2):289-90.

4. Gulur DM, Mevcha AM, Drake MJ. Nocturia as a manifestation of systemic disease. BJU Int. 2011;107(5):702-13.

5. Nimeh T, Alvarez P, Mufarreh N, Lerner L. Nocturia: Current Evaluation and Treatment for Urology. Curr Urol Rep. 2015;16(9):66.

6. Oelke M, Adler E, Marschall-Kehrel D, Herrmann TR, Berges R Nocturia: state of the art and critical analysis of current assessment and treatment strategies World J Urol 2014;32(5):1109-17.

7. Rosen R, Holm-Larsen T, Kupelian V, Wein AJ. . Consequences of nocturia Postgrad Med. 2013;125(4):38-46.

8. Booth J, Lawrence M, O'Neill K, McMillan L Exploring older peoples' experiences of nocturia: a poorly recognised urinary condition that limits participation. Disabil Rehabil. 2010;32(9):765-74.

9. Bower WF EC, Whishaw DM, Khan F. . Development of a Long- Form Screening Tool for Identifying Clinically Relevant Co-Morbidities of Nocturia. Australia and New Zealand Continence Journal 2016;22(2):40-7

10. Avulova S, Blanker MH, van Doorn B, Weiss JP, Bosch JR, Tsui JF, et al. Determinants of nocturia severity in men, derived from frequencyâ€ $€$ "volume charts. Scandinavian journal of urology. 2015;49(2):185-8.

11. Weiss JP. Nocturia:"Do the math"• . The Journal of urology. 2006;175(3):S16-S8.

12. Temml C, Ponholzer A, Gujahr G, Berger I, Marszalek M, Madersbacher S. Nocturia is an age-independent risk factor for hip fractures in men. Neurourol and Urodyn. 2009;28(8):949-52. 
13. Brunner A, Riss P. Nocturia in women. Maturitas. 2011;70(1):16-21.

14. Ayik S, Bal K, Akhan G. The association of nocturia with sleep disorders and metabolic and chronic pulmonary conditions: data derived from the polysomnographic evaluations of 730 patients. Turk J Med Sc. 2014;44(2):249-54.

15. Miyauchi Y, Okazoe H, Okujyo M, Inada F, Kakehi T, Kikuchi H, et al. Effect of the continuous positive airway pressure on the nocturnal urine volume or night-time frequency in patients with obstructive sleep apnea syndrome. Urology. 2015;85(2):333-

6.

16. Bliwise DL, Holm-Larsen T, Goble S, NÃ, rgaard JP. Short time to first void is associated with lower whole-night sleep quality in nocturia patients. Journal of clinical sleep medicine: JCSM: official publication of the American Academy of Sleep Medicine. 2015;11(1):53.

17. Breyer BN, Shindel AW, Erickson BA, Blaschko SD, Steers WD, Rosen RC. The association of depression, anxiety and nocturia: a systematic review. J Urol. 2013;190(3):953-7.

18. Van Kerrebroeck P. Nocturia: current status and future perspectives. Curr Opin Obstet Gynecol. 2011;23(5):376-85.

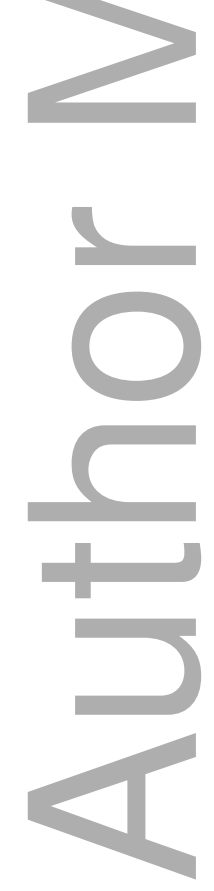


Place a tick $\square$ next to each statement which is TRUE / CORRECT for you.

\begin{tabular}{|c|}
\hline My ankles, feet or legs swell during the day. \\
\hline I take fluid tablets (e.g. Lasix). \\
\hline I have kidney disease. \\
\hline I take tablets to control my blood pressure. \\
\hline I often get dizzy when standing up. \\
\hline I have high blood sugar OR diabetes. \\
\hline My blood sugar levels are difficult to keep stable. \\
\hline
\end{tabular}

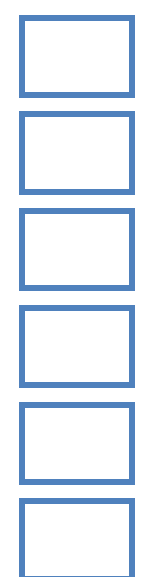

I have 5 hours or less sleep per night.

I would describe my sleep quality as bad.

It takes me longer than 30 minutes to fall asleep at night.

I have difficulty staying asleep at night because of my bladder.

I often experience pain at night.

I have been told I snore loudly OR stop breathing at night.

I need to get up to pass urine within 3 hours of going to sleep.

I experience a sudden urge to urinate on most days.

I have a bladder urgency accident once a week or more.

I often need to strain or push to start urinating.

I have an enlarged prostate gland. (MALES ONLY)

In general, I would say that my health is not good.

I have trouble staying awake while driving, eating or during social activities.

I have had a fall in the last 3 months.

I don't look forward to things with as much enjoyment as I used to.

This article is protected by copyright. All rights reserved 


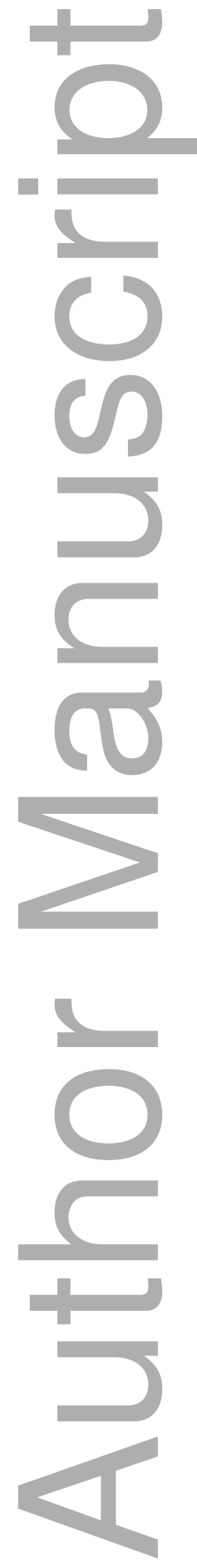

This article is protected by copyright. All rights reserved 
Table 1: Demographic characteristics of participants in the study

\begin{tabular}{|c|c|c|c|c|}
\hline & $\begin{array}{c}\text { Overall } \\
(n, \%)\end{array}$ & $\begin{array}{c}\text { Continence Clinic } \\
(n, \%)\end{array}$ & $\begin{array}{c}\text { Sleep Clinic } \\
(n, \%)\end{array}$ & $\begin{array}{c}\text { Other Services } \\
(n, \%)\end{array}$ \\
\hline No. of patients & 252 & $107(42.5 \%)$ & $100(39.7 \%)$ & 45 (17.9\%) \\
\hline \multicolumn{5}{|l|}{ Gender } \\
\hline Male & $125(49.6 \%)$ & $38(35.5 \%)$ & $60(60.0 \%)$ & $27(60.0 \%)$ \\
\hline Female & $126(50.0 \%)$ & 68 (63.6\%) & 40 (40.0\%) & $18(40.0 \%)$ \\
\hline No response & $1(0.4 \%)$ & $1(0.9 \%)$ & $0(0.0 \%)$ & $0(0.0 \%)$ \\
\hline Mean Age (yrs) & $64.8+/-12.8$ & $68.14+/-12.7$ & $59.17+/-10.7$ & $69.2+/-13.2$ \\
\hline \multicolumn{5}{|l|}{ Age Group } \\
\hline 40 to $49 y r s$ & $42(16.7 \%)$ & $15(14.0 \%)$ & $22(22.0 \%)$ & $5(11.1 \%)$ \\
\hline 50 to $59 \mathrm{yr}$ & $41(16.3 \%)$ & $12(11.2 \%)$ & $26(26.0 \%)$ & $3(6.7 \%)$ \\
\hline 60 to $69 \mathrm{yrs}$ & $75(29.8 \%)$ & $28(26.2 \%)$ & $33(33.0 \%)$ & $14(31.1 \%)$ \\
\hline 70 to $79 \mathrm{yrs}$ & $56(22.2 \%)$ & $28(26.2 \%)$ & $18(18.0 \%)$ & $10(22.2 \%)$ \\
\hline$\geq 80 \mathrm{yrs}$ & $38(15.1 \%)$ & 24 (22.4\%) & $1(1.0 \%)$ & $13(28.9 \%)$ \\
\hline \multicolumn{5}{|l|}{ Education Level } \\
\hline Middle School or below & $75(29.8 \%)$ & $29(27.1 \%)$ & $28(28.0 \%)$ & $18(40.0 \%)$ \\
\hline Senior High School & $59(23.4 \%)$ & $31(29.0 \%)$ & $18(18.0 \%)$ & $10(22.2 \%)$ \\
\hline Trade/Vocatio & $55(21.8 \%)$ & $24(22.4 \%)$ & $24(24.0 \%)$ & $7(15.6 \%)$ \\
\hline University or above & $58(23.0 \%)$ & $20(18.7 \%)$ & $28(28.0 \%)$ & $10(22.2 \%)$ \\
\hline No response & $5(2.0 \%)$ & $3(2.8 \%)$ & $2(2.0 \%)$ & $0(0.0 \%)$ \\
\hline \multicolumn{5}{|l|}{ Living Status } \\
\hline Alone & $65(25.8 \%)$ & $28(26.2 \%)$ & $23(23.0 \%)$ & $14(31.1 \%)$ \\
\hline No response & $91(36.1 \%)$ & $34(31.8 \%)$ & $25(25.0 \%)$ & $32(71.1 \%)$ \\
\hline \multicolumn{5}{|l|}{ Working Status } \\
\hline Working & $65(25.8 \%)$ & $22(20.6 \%)$ & $37(37.0 \%)$ & $6(13.3 \%)$ \\
\hline Retired/ not working & $114(45.2 \%)$ & $49(45.8 \%)$ & $43(43.0 \%)$ & 22 (48.9\%) \\
\hline No response & $84(33.3 \%)$ & $36(33.6 \%)$ & $20(20.0 \%)$ & $28(62.2 \%)$ \\
\hline \multicolumn{5}{|l|}{ IRSAD $^{\#}$} \\
\hline Lowest 40\% & 89 & $39(36.4 \%)$ & $39(39 \%)$ & $11(24.4 \%)$ \\
\hline No response & $5(2.0 \%)$ & $3(2.8 \%)$ & $0(0 \%)$ & $2(4.4 \%)$ \\
\hline
\end{tabular}

* Other Services: Rehabilitation, Falls and Balance Clinic, Rehabilitation Ward, Aged Care Ward \# IRSAD = Index of Social Advantage and Disadvantage by Postal Area (ABS, 2011) 
Table 2: Physical characteristics of participants in the study

\begin{tabular}{|c|c|c|c|c|}
\hline & $\begin{array}{l}\text { Overall } \\
(n=252)\end{array}$ & $\begin{array}{l}\text { Continence Clinic } \\
\qquad(n=107)\end{array}$ & $\begin{array}{l}\text { Sleep Clinic } \\
\qquad(n=100)\end{array}$ & $\begin{array}{l}\text { Other Services* } \\
\qquad(n=45)\end{array}$ \\
\hline Mean BMI & $\begin{array}{c}n=243 \\
31.2+/-7.5\end{array}$ & $\begin{array}{c}n=103 \\
29.3+/-6.0\end{array}$ & $\begin{array}{c}n=98 \\
34.1+/-7.9\end{array}$ & $\begin{array}{c}n=42 \\
29.2+/-7.7\end{array}$ \\
\hline $\begin{array}{l}\text { Mean Waist to Hip Ratio } \\
\text { Male } \\
\text { Female }\end{array}$ & $\begin{array}{c}n=122 \\
1.0+/-0.07 \\
n=120 \\
0.90+/-0.07\end{array}$ & $\begin{array}{c}n=36 \\
0.98+/-0.07 \\
n=67 \\
0.90+/-0.07\end{array}$ & $\begin{array}{c}n=60 \\
1.02+/-0.07 \\
n=37 \\
0.90+/-0.05\end{array}$ & $\begin{array}{c}n=26 \\
0.96+/-0.06 \\
n=16 \\
0.91+/-0.05\end{array}$ \\
\hline $\begin{array}{l}\text { Mean Systolic Bloo } \\
\text { Pressure }\end{array}$ & $\begin{array}{c}n=237 \\
132+/-18.4\end{array}$ & $\begin{array}{c}n=104 \\
135.4+/-20.8\end{array}$ & $\begin{array}{c}n=92 \\
129.7+/-16.5\end{array}$ & $\begin{array}{c}n=41 \\
133.3+/-14.8\end{array}$ \\
\hline $\begin{array}{l}\text { Mean Diastolic Blood } \\
\text { Pressure }\end{array}$ & $\begin{array}{c}n=237 \\
77.36+/-9.6\end{array}$ & $\begin{array}{c}n=104 \\
77.2+/-9.0\end{array}$ & $\begin{array}{c}n=92 \\
77.5+/-10.8\end{array}$ & $\begin{array}{c}n=41 \\
77.5+/-8.6\end{array}$ \\
\hline $\begin{array}{l}\text { Evidence of Postural } \\
\text { Hypotension }(n, \%)\end{array}$ & $56(22.2 \%)$ & $\begin{array}{c}n=107 \\
19(17.8 \%)\end{array}$ & $\begin{array}{c}n=100 \\
25(25 \%)\end{array}$ & $\begin{array}{c}n=45 \\
12(26.7 \%)\end{array}$ \\
\hline $\begin{array}{l}\text { Timed Up and Go Test } \\
\text { (median, IQR) }\end{array}$ & $\begin{array}{c}n=223 \\
10.0 \\
\text { (8.0 to } 14.3)\end{array}$ & $\begin{array}{c}n=103 \\
10.3 \\
(8.0 \text { to } 15.0)\end{array}$ & $\begin{array}{c}n=84 \\
10.1 \\
(8.0 \text { to } 13.5)\end{array}$ & $\begin{array}{c}n=36 \\
9.1 \\
(7.2 \text { to } 9.1)\end{array}$ \\
\hline
\end{tabular}

* Other Services: Rehabilitation, Falls and Balance Clinic, Rehabilitation Ward, Aged Care Ward 
Table 3: Evaluation grid justifying items retained in the TANGO SF

\begin{tabular}{|c|c|c|c|c|c|c|}
\hline Name of Variable & $\begin{array}{l}\text { Univariate linear } \\
\text { regression with } \\
\text { nocturia frequency }\end{array}$ & $\begin{array}{l}\text { Clinically important } \\
\text { value / score }\end{array}$ & $\begin{array}{l}\text { Responses with clinically } \\
\text { important score (\%) }\end{array}$ & $\begin{array}{l}\text { Floor effect: proportion of non- } \\
\text { problematic option endorsed (\%) }\end{array}$ & $\begin{array}{c}\text { Missing } \\
\text { data } n(\%)\end{array}$ & $\begin{array}{l}\text { Inter-correlations between } \\
\text { predictor variables }\end{array}$ \\
\hline \multicolumn{7}{|l|}{ Demographic } \\
\hline Age & $\begin{array}{l}R^{2}=0.020 \\
p=0.023\end{array}$ & -- & --- & --- & $1(0.4)$ & --- \\
\hline \multicolumn{7}{|l|}{ Physical Measures } \\
\hline Timed Up and Go Test & $\begin{array}{l}R^{2}=0.052 \\
p=0.001\end{array}$ & $\begin{array}{c}>13.5 \mathrm{sec} \\
\text { "increased risk of falling" }\end{array}$ & 28.3 & --- & $29(11.5)$ & --- \\
\hline \multicolumn{7}{|l|}{ Wellbeing } \\
\hline General Health & $\begin{array}{l}R^{2}=0.037 \\
p=0.002\end{array}$ & Fair to poor health & 45.4 & 22.7 & $1(0.4)$ & $\begin{array}{c}\text { Spearman's rho 0.392, } \\
p<0.001 \text { with Pain/Discomfort. }\end{array}$ \\
\hline Pain /Discomfort & $\begin{array}{l}R^{2}=0.024 \\
p=0.015\end{array}$ & $\begin{array}{c}\text { Moderate to severe pain / } \\
\text { discomfort }\end{array}$ & 54.3 & 20.9 & $3(1.2)$ & $\begin{array}{l}\text { See General Health and } \\
\text { Sleep Pain. }\end{array}$ \\
\hline \multicolumn{7}{|c|}{ Cardiovāscular / Metabolic } \\
\hline Leg Swelling & $\begin{array}{l}R^{2}=0.027 \\
p=0.010\end{array}$ & Yes to leg swelling & 49.8 & 50.2 & $3(1.2)$ & $\begin{array}{l}\text { See Hypertension, Kidney } \\
\text { Disease and Fluid } \\
\text { Medications. }\end{array}$ \\
\hline Kidney Disease & $\begin{array}{l}R^{2}=0.025 \\
p=0.017\end{array}$ & Yes to kidney disease & 7.7 & 92.3 & $19(7.5)$ & $\begin{array}{l}\text { Pearson's r } 0.139, p=0.035 \\
\text { with Leg Swelling. }\end{array}$ \\
\hline \multicolumn{7}{|l|}{ Urinary Tract } \\
\hline Time to Nocturia & $\begin{array}{l}R^{2}=0.144 \\
p=0.001\end{array}$ & $<3$ hours & 40 & $\begin{array}{c}4.1 \\
\text { (>6 hours) }\end{array}$ & $12(4.8)$ & --- \\
\hline
\end{tabular}

This article is protected by copyright. All rights reserved 


\begin{tabular}{|c|c|c|c|c|c|c|}
\hline Sudden Urgency & $\begin{array}{l}R^{2}=0.085 \\
p<0.001\end{array}$ & Daily or more often & 64.4 & 16.4 & $2(0.8)$ & $\begin{array}{l}\text { Pearson's r } 0.485, p<0.001 \\
\text { with Urgency Incontinence }\end{array}$ \\
\hline Strain (MEN ONLY) & $\begin{array}{l}R^{2}=0.059 \\
p=0.007\end{array}$ & Sometimes or often & 32.5 & 52.0 & $2(0.8)$ & --- \\
\hline Urgency Incontinence & $\begin{array}{l}R^{2}=0.051 \\
p<0.001\end{array}$ & Daily or more often & 40.9 & 37.3 & $3(1.2)$ & See Sudden Urgency. \\
\hline Name of Variable & $\begin{array}{l}\text { Univariate linear } \\
\text { regression with } \\
\text { nocturia frequency }\end{array}$ & $\begin{array}{l}\text { Clinically important } \\
\text { value / score }\end{array}$ & $\begin{array}{l}\text { Responses with clinically } \\
\text { important score (\%) }\end{array}$ & $\begin{array}{l}\text { Floor effect: proportion of non- } \\
\text { problematic option endorsed (\%) }\end{array}$ & $\begin{array}{c}\text { Missing } \\
\text { data } n(\%)\end{array}$ & $\begin{array}{l}\text { Inter-correlations between } \\
\text { predictor variables }\end{array}$ \\
\hline \multicolumn{7}{|c|}{ Anxiety and Depression } \\
\hline Enjoyment & $\begin{array}{l}R^{2}=0.03 \\
p=0.006\end{array}$ & Only a little to hardly at all & 19 & 36.7 & $4(1.6)$ & --- \\
\hline Cheerful & $\begin{array}{l}R^{2}=0.020 \\
p=0.028\end{array}$ & Not often to not at all & 14.1 & 53.2 & $4(1.6)$ & --- \\
\hline $\begin{array}{l}\text { Disinterest in } \\
\text { appearance }\end{array}$ & $\begin{array}{l}R^{2}=0.019 \\
p=0.031\end{array}$ & I don't take care & 22.9 & 48.8 & $4(1.6)$ & --- \\
\hline Optimism & $\begin{array}{l}R^{2}=0.036 \\
p=0.003\end{array}$ & Less / hardly at all & 23.3 & 47.6 & $4(1.6)$ & $\begin{array}{c}\text { Spearman's rho } 0.608 \text {, } \\
\text { p<0.001 with HADS } \\
\text { Depression. }\end{array}$ \\
\hline HADS Depression & $\begin{array}{l}R^{2}=0.046 \\
p=0.001\end{array}$ & $\begin{array}{l}11 \text { to } 21 \\
\text { "Abnormal" }\end{array}$ & 11.4 & --- & $6(3.6)$ & See Optimism. \\
\hline
\end{tabular}

This article is protected by copyright. All rights reserved 


\begin{tabular}{|c|c|c|c|c|c|c|}
\hline Staying Asleep & $\begin{array}{l}R^{2}=0.100 \\
p<0.001\end{array}$ & Often to always & 42.3 & 24.4 & $18(7.1)$ & $\begin{array}{l}\text { Spearman's rho } 0.544 \text {, } \\
p<0.001 \text { with Sleep Quality. }\end{array}$ \\
\hline Time to Sleep & $\begin{array}{l}R^{2}=0.051 \\
p<0.001\end{array}$ & $>30 \mathrm{mins}$ & 24.2 & $\begin{array}{c}5.8 \\
(<5 \text { mins })\end{array}$ & $12(4.8)$ & $\begin{array}{l}\text { Pearson's r } 0.214, p=0.001 \\
\text { with Sleep Quality. }\end{array}$ \\
\hline Hours Bed & $\begin{array}{l}R^{2}=0.018 \\
p=0.033\end{array}$ & $\begin{array}{l}<6 \mathrm{hrs} \\
>10 \mathrm{hrs}\end{array}$ & $\begin{array}{l}2.4 \\
16.9\end{array}$ & -- & $4(1.6)$ & $\begin{array}{l}\text { Spearman's rho }-0.031 \text {, } \\
p=0.624 \text { with Sleep Quality. }\end{array}$ \\
\hline Hours & $\begin{array}{l}R^{2}=0.035 \\
p=0.003\end{array}$ & $\begin{array}{l}<6 \text { hrs } \\
>8 \mathrm{hrs}\end{array}$ & $\begin{array}{l}35.1 \\
13.1\end{array}$ & $\begin{array}{c}5.7 \\
\text { (<4 hours) }\end{array}$ & $7(2.8)$ & $\begin{array}{l}\text { Spearman's rho }-0.517 \text {, } \\
p<0.001 \text { with Sleep Quality. }\end{array}$ \\
\hline Sleep Pain & $\begin{array}{l}R^{2}=0.041 \\
p=0.001\end{array}$ & Weekly or more often & 41.7 & 43.8 & $10(4.0)$ & $\begin{array}{c}\text { Spearman's rho } 0.572, \\
p<0.001 \text { with Pain/Discomfort. }\end{array}$ \\
\hline Sleep Quality & $\begin{array}{l}R^{2}=0.071 \\
p<0.001\end{array}$ & Fairly bad to very bad & 33.1 & 12.9 & $4(1.6)$ & $\begin{array}{l}\text { See Staying Asleep, Time to } \\
\text { Sleep, Hours Bed and Hours } \\
\text { Sleep. }\end{array}$ \\
\hline Global PSQI & $\begin{array}{l}R^{2}=0.075 \\
p<0.001\end{array}$ & $\begin{array}{c}>5 \text { equals } \\
\text { "Poor sleep quality" }\end{array}$ & 73.4 & 26.6 & $60(23.8)$ & \\
\hline
\end{tabular}

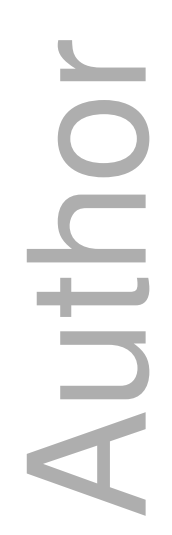

This article is protected by copyright. All rights reserved 


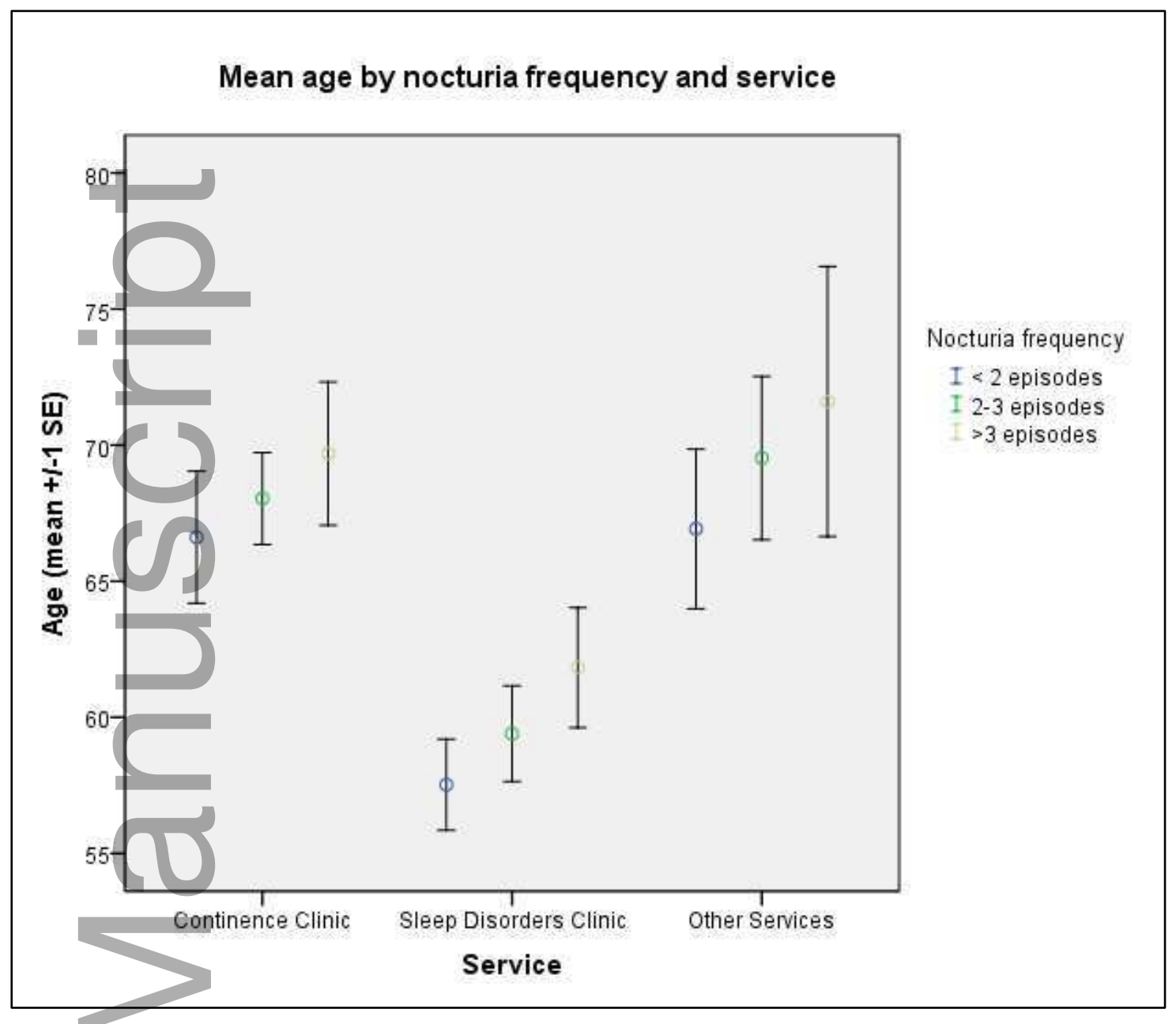

Figure 1: Frequency of nocturia in continence and sleep patients

This article is protected by copyright. All rights reserved 


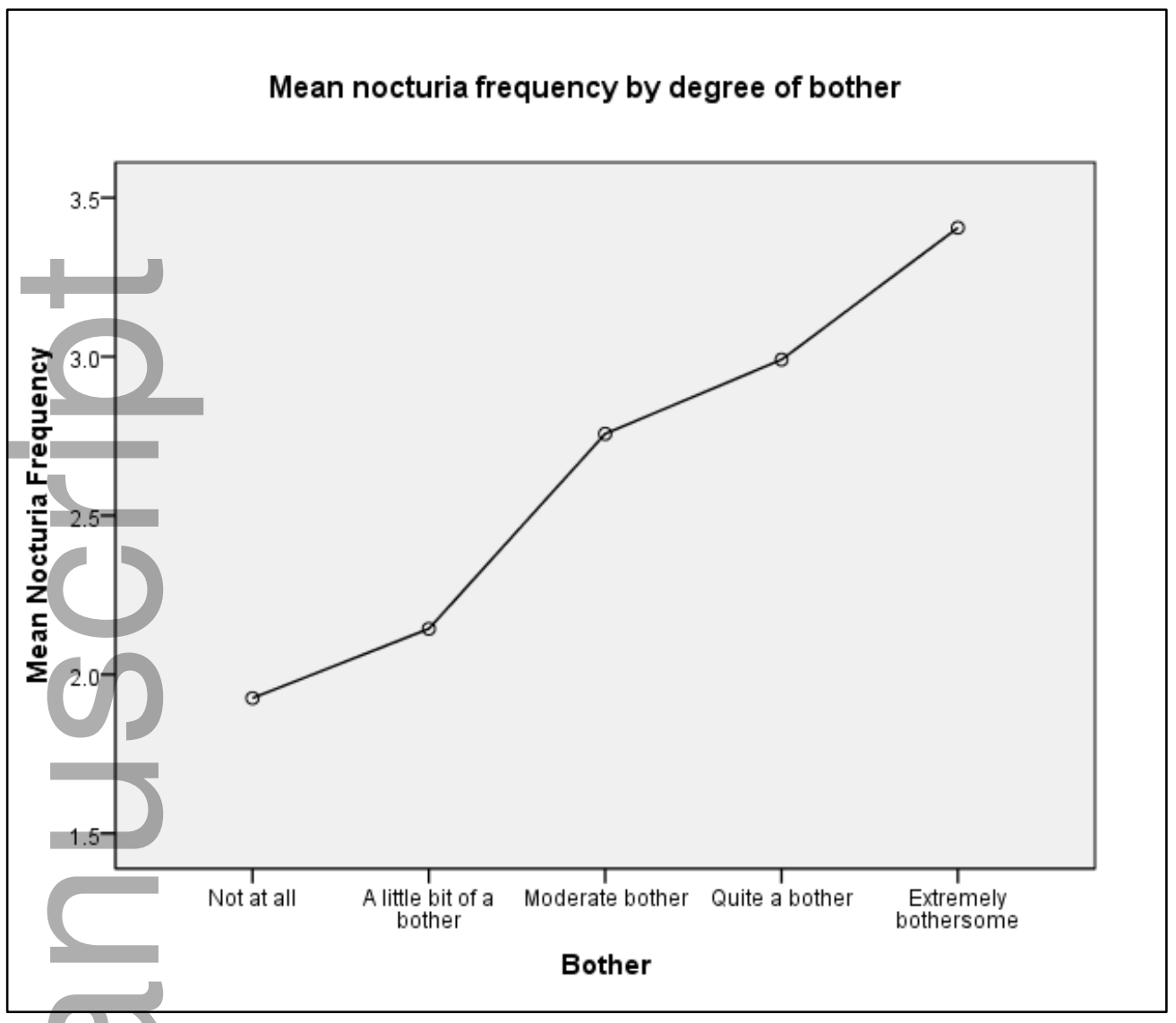

Figure 2: Relationship between nocturia frequency and degree of bother

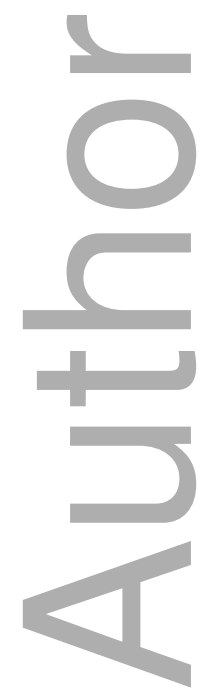

This article is protected by copyright. All rights reserved 
-TANGO Long Form: 57 questions; 10 physical measures.

- Removal of demographic items designed for descriptive analyses only.

-Removal of items with poor endorsement (>20\% missing data).

- Removal of items with a high floor effect ( $>70 \%$ responses 'never' or its equivalent).

- Removal of items of low clinical relevance and/or those non-

significantly associated with nocturia severity.

- Removal of redundant items showing high agreement with other items (i.e an inter-relationship > 0.6)

-TANGO Short Form; 22 statements across 4 domains

Figure 3: Decision tree for generating items to be retained in TANGO short form

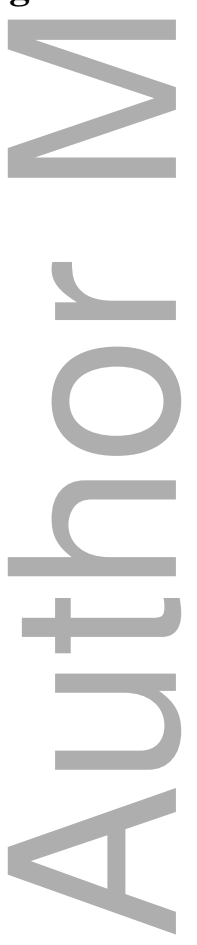

This article is protected by copyright. All rights reserved 


\section{University Library}

\section{- M M N E R VA A gateway to Melbourne's research publications}

Minerva Access is the Institutional Repository of The University of Melbourne

Author/s:

Bower, WF;Rose, GE;Ervin, CF;Goldin, J;Whishaw, DM;Khan, F

Title:

TANGO - a screening tool to identify comorbidities on the causal pathway of nocturia

Date:

2017-06-01

Citation:

Bower, W. F., Rose, G. E., Ervin, C. F., Goldin, J., Whishaw, D. M. \& Khan, F. (2017).

TANGO - a screening tool to identify comorbidities on the causal pathway of nocturia. BJU INTERNATIONAL, 119 (6), pp.933-941. https://doi.org/10.1111/bju.13774.

Persistent Link:

http://hdl.handle.net/11343/292438 